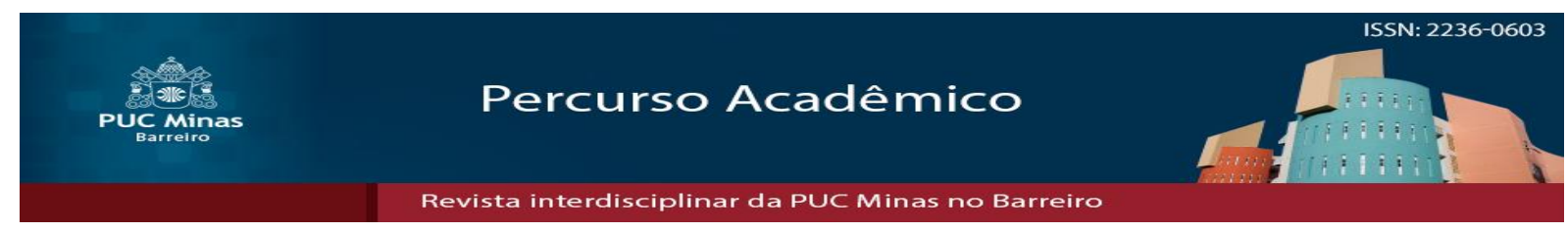

\title{
O combate à corrupção e os riscos aos direitos fundamentais
}

\section{The fight against corruption and the risk to fundamental rights}

\author{
Stefan Hanatzki Siglinski ${ }^{1}$ \\ Janiquele Wilmsen $^{2}$
}

\section{Resumo}

O combate à corrupção é questão atual que ganha força com o crescente desprestígio da classe política, diante da má administração e da falta de recursos para fazer frente às necessidades básicas da população. A cobrança por uma resposta adequada do Poder Judiciário, diante da ameaça que a corrupção representa para a democracia e para o desenvolvimento do Estado, ao enfraquecer as instituições nacionais e os valores democráticos, tem ocasionado a flexibilização de determinadas garantias processuais penais, no afã de assegurar a punição de supostos infratores. Diante disso, a pesquisa objetiva analisar os riscos que o combate à corrupção pode ocasionar aos direitos fundamentais. Para atingir o objetivo, utilizou-se fonte de pesquisa imediata formal e método de abordagem dedutivo. Conclui-se que o combate à corrupção mediante a adoção de estratégias preventivas pode ser mais eficaz do que o seu combate mediante estratégias repressivas, as quais podem ocasionar riscos aos direitos fundamentais e atritos entre os poderes, ocasionando a criação de um vácuo de poder, que pode ser preenchido por homens de inspiração autoritária.

Palavras-chave: Combate à corrupção. Democracia. Direitos fundamentais. Flexibilização de garantias.

\begin{abstract}
The fight against corruption is a current issue that gains strength with the growing discredit of the political class in the face of maladministration and the lack of resources to meet the basic needs of the population. The collection by an adequate response of the Judiciary, due to the threat that corruption poses to democracy and to the development of the State, by weakening national institutions and democratic values, has resulted in

\footnotetext{
Artigo recebido em 19 de Outubro de 2017 e aprovado em 01 de Março de 2019.

${ }^{1}$. Mestre em Direito pela Universidade de Passo Fundo - UPF. Bacharel em Direito pelo Instituto Cenecista de Ensino Superior de Santo Ângelo (IESA). Professor de Direito Penal e Direito Processual Penal na Faculdade do Vale do Juruena, Brasil. E-mail: stefan_siglinski@ hotmail.com

${ }^{2}$ Mestrado em Direito pela Universidade de Passo Fundo, Brasil(2018), Advogada, Brasil. E-mail: janiquelewilmsen@hotmail.com
} 
the flexibilization of certain procedural guarantees of criminal law, in the effort to ensure the punishment of alleged offenders. Faced with this, the research aims to analyze the risks that the fight against corruption can cause fundamental rights. To achieve the objective, we used immediate formal research source and method of deductive approach. It is concluded that the fight against corruption through the adoption of preventive strategies can be more effective than its combat through repressive strategies, which can cause risks to fundamental rights and attrition between the powers, causing the creation of a vacuum of power, which can be filled by men of authoritative inspiration.

Key-words: Fight agaisnt corruption. Democracy. Fundamental rights. Flexibilization of guarantees.

\section{Introdução}

A corrupção é um problema que historicamente assola a sociedade. Por sua prática envolver, em regra, cidadãos ligados aos centros de poder político ou com grande poder econômico, e ser cometida de forma mais elaborada e oculta, o que dificulta a prova da autoria e materialidade, seu enfrentamento por meios repressivos ocasiona atritos entre os poderes do Estado.

De difícil combate e com efeitos danosos para o desenvolvimento nacional, ao promover desestabilidade fiscal e social, deslegitimar o sistema político, jurídico e as instituições do país, e desestimular o mercado, sua prática ameaça o regime democrático, a manutenção da ordem jurídica e a moral social.

O enfrentamento do problema por meio de repressão e punição, pelas características do delito, aliado ao fato de o Ministério Público e de o Poder Judiciário buscarem de todas as maneiras dar efetividade ao Direito Penal, coloca em risco os direitos e garantias fundamentais, ante a flexibilização de determinadas garantias processuais penais, necessárias para garantir a legitimidade da persecução penal.

Diante disso, propõe-se uma reflexão sobre os riscos do combate à corrupção para os direitos fundamentais, com uma abordagem conceitual de corrupção, seus efeitos para o regime democrático e a crescente criminalização de condutas corruptas, bem como uma análise sobre os riscos que seu combate pode ocasionar ao regime democrático, caso desrespeitados os direitos e garantias fundamentais. Para atingir o 
objetivo, utilizou-se fonte de pesquisa imediata formal e método de abordagem dedutivo.

\title{
2 Corrupção: conceito, efeitos e criminalização
}

O vocábulo corrupção é utilizado no Código Penal pátrio para a formatação de diversos tipos penais. No entanto, o presente trabalho tem por objetivo o estudo da corrupção enquanto prática criminosa perpetrada contra a Administração Pública. Isso porque, embora também possa ser encontrada na esfera privada, quando efetivada na esfera pública, as consequências da corrupção são ampliadas diante do reflexo negativo da sua prática em diversos setores da sociedade e do maior grau de abrangência dos seus efeitos, os quais atingem toda a sociedade de maneira direta, diante do interesse e dos recursos públicos em jogo.

Norberto Bobbio, Nicola Matteucci e Gianfranco Pasquino [1976]/(1998) definem corrupção como um fenômeno no qual "um funcionário público é levado a agir de modo contrário dos padrões normativos do sistema, favorecendo interesses particulares em troca de recompensa. Corrupto é, portanto, o comportamento ilegal de quem desempenha um papel na estrutura estatal" (BOBBIO; MATTEUCCI; PASQUINO, 1998, p. 291).

A organização não-governamental Transparência Internacional (TI), ao definir a prática da corrupção, conforme afirma Gesner Oliveira (2009), o faz associando-a ao poder. Assim, para a Transparência Internacional, a corrupção pode ser definida como "um abuso de poder para auferir ganho privado" (apud OLIVEIRA, 2009, p. 166).

Em seu sentido etimológico, segundo Márcia Noll Barboza (2006), o vocábulo corrupção advém,

\begin{abstract}
do termo latino corruptione, cujo significado primeiro era o de adulteração, decomposição, putrefação, relativo a alimentos ou outros materiais. Em sentido figurado, significava perversão, devassidão, depravação, aplicável a pessoas, regimes políticos etc. Nos idiomas derivados do latim e também na língua inglesa, o termo, devidamente recepcionado (e adaptado), apareceu em estudos filosóficos e políticos para expressar perversão de um regime. Só mais tarde é que assumiu o significado contemporâneo de uso indevido do poder em troca de vantagens econômicas ou de outro tipo. Tais significados, ainda que próximos, distinguem-se: o primeiro alude a um regime todo ele pervertido, comprometido; o segundo, a determinadas práticas e condutas, que podem existir em maior ou menor quantidade, comprometendo ou não o sistema. (BARBOZA, 2006, p. 109).
\end{abstract}


Ainda, conforme definição de Mário Pimentel Albuquerque (2006), corrupção é um ato "clandestino praticado por duas ou mais pessoas, dentre as quais, pelo menos uma revestida de poder decisório, mediante o qual, em flagrante violação ao dever posicional, perseguem-se vantagens econômicas ou não, sem fundamento no sistema normativo relevante" (ALBUQUERQUE, 2006, p. 19).

Ernesto Garzón Valdés (2004) propõe a definição de corrução nos seguintes termos:

La corrupción consiste en la violación limitada de una obligación por parte de uno o más decisores con el objeto de obtener un beneficio personal extraposicional del agente que lo(s) soborna o a quien extorsiona(n) a cambio del otorgamiento de beneficios para el sobornante o el extorsionado que superan los costes del soborno o del pago o servicio extorsionado. (VALDÉS, 2004, p. 14).

Desse modo, a prática da corrupção está atrelada ao exercício do poder por agentes públicos de maneira abusiva, via perversão da coisa pública, cuja manifestação ocorre pela prática, abstenção ou retardamento na execução de determinadas condutas, em evidente violação ao dever funcional e ao interesse público, com o objetivo de auferir algum benefício pessoal.

Embora no momento atual os escândalos de corrupção têm deixado esses atos em evidência, a prática de ações dessa natureza não é problema exclusivamente contemporâneo. Conforme afirma Barboza (2006), “[...] a prática de atos corruptos em torno aos centros de poder é algo recorrente na história, é algo que acompanha o homem em sua trajetória de organização e progresso, sem jamais o deixar, como se de sua sombra se tratasse" (BARBOZA, 2006, p. 89).

A ocorrência de atos corruptos pode incidir com maior ou menor intensidade, dependendo das causas e condicionantes serem ou não propícias à sua prática, mas não deixarão de ocorrer por completo. Sua extinção não parece uma tarefa viável, haja vista sua prática ser silenciosa e discreta, com ocultação e dissimulação das condutas ilícitas, o que dificulta sua prova e, consequentemente, seu combate.

Dentre as inúmeras causas e condicionantes favoráveis à prática de atos corruptos, destacam-se a ainda precária transparência pública, a excessiva concentração de poder por parte de determinados agentes públicos e a desenfreada competição dos 
agentes econômicos em prol da maximização dos lucros que, aliada à possibilidade de contribuição privada para o financiamento de campanhas eleitorais, estimula a troca de favores entre agentes públicos e privados e favorece a influência da iniciativa privada sobre a classe política.

Além do mais, o momento atual é oportuno à prática da corrupção diante da onda neoliberal em ascensão, cujos elementos propiciam o desenvolvimento desta espécie de criminalidade. Dentre esses elementos, destacam-se:

\begin{abstract}
internacionalização e liberalização das relações comerciais e do sistema financeiro, diminuição ou eliminação dos controles estatais, conversão de um bloco de países ao regime capitalista, expansão da cultura do consumo e da lógica da maximização do lucro, formação de grandes organizações (empresariais) com enorme poder econômico, intensificação da informação e da comunicação, entre outros. (BARBOZA, 2006, p. 91).
\end{abstract}

Esses elementos, causas e condicionantes tornam qualquer órgão estatal suscetível à corrupção. Desse modo, é indispensável leva-las constantemente em consideração na físcalização dos órgãos públicos, de modo a tornar possível detectar os abusos perpetrados, para que sejam tolhidos antes do enraizamento na estrutura governamental.

Neste sentido, afirma Humberto Jacques de Medeiros (2006) que, qualquer “organização estatal é passível de ser corrompida. É necessário que não se ignore a vulnerabilidade de todas as organizações à corrupção, sob pena de somente se descobrila quando ela já se tenha alastrado em demasia, a ponto de sufocar o tecido organizado" (MEDEIROS, 2006, p. 58).

Da mesma forma, Aristóteles (2001), ao afirmar que é conhecendo os meios pelos quais se dissolvem e corrompem os Estados, que torna possível saber os meios de conservá-lo, ensina que, num Estado bem constituído, deve-se:

[...] observar cuidadosamente que nada se faça contra as leis e os costumes, e sobretudo prestar atenção, desde o começo, nos abusos, por pequenos que sejam. A corrupção introduz-se imperceptivelmente; é que, como as pequenas despesas, repetidas, consomem o património de uma família. Só se sente o mal quando está consumado. Como ele não acontece de uma vez, seus progressos escapam ao entendimento e se parecem àquele sofisma que do fato de cada parte ser pequena infere que o todo seja pequeno. Ora, se é indubitável que o total seja composto de coisas pequenas, é falso que ele próprio seja pequeno. O ponto capital, portanto, é deter o mal desde o começo. (ARISTÓTELES, 2001, p. 136). 
Ainda, quanto à sua inextinguibilidade, afirma Medeiros (2006) que, além de ardilosa "a corrupção estatal é permanente. Nunca poderá ser extirpada como um todo. Sempre residirá, ainda que latente, em algum espaço da máquina do Estado. Tanto lhe é impossível se adonar de todo o Estado como alhear-se por completo dele" (MEDEIROS, 2006, p. 58).

Seus efeitos são danosos para o regime democrático, para a manutenção da ordem jurídica e da moral social, uma vez que põe à prova as instituições encarregadas da investigação e repressão às práticas delitivas, propicia a crise de legitimidade do sistema político e das instituições públicas, promove desestabilidade social, aumenta os custos e preços dos bens e serviços e desestimula o desenvolvimento econômico do país.

Neste sentido, quanto ao aumento dos custos e preços dos bens e serviços, embora não seja tarefa fácil estimar em que proporção a corrupção influi neles, Jorge F. Malem Seña oferece dois exemplos para ilustrar o impacto negativo dessa prática na economia. Segundo o doutrinador, em Milão, na Itália, depois dos processos reunidos sob o rótulo "Operação Mãos Limpas" “[...] el coste por kilómetro de la línea del metro cayó en un $57 \%$. Y el presupuesto para la construcción de la nueva terminal del aeropuerto se redujo en el 59\% como consecuencia de una bajada en los costes de construcción” (SEÑA, 2001, p. 585).

Já na Rússia, segundo Seña (2001), desde a queda do muro de Berlim, a corrupção alastrou-se vertiginosamente. Para ilustrar sua influência, cita o caso do mercado alimentício controlado pelas máfias, as quais fixavam o preço dos bens e serviços envolvidos. Com a atuação da polícia e da KGB na proteção dos comerciantes contra a ação da máfia, o preço dos produtos teve redução entre quinze e vinte por cento.

Ainda sobre a Operação Mãos Limpas, na Itália, e os custos da corrupção para aquele país, afirma Sérgio Fernando Moro (2004) que a Operação "serviu para interromper a curva ascendente da corrupção e de seus custos. Giuseppe Turani, jornalista financeiro italiano, estimou que, na década de 1980-1990, a corrupção teria custado à Itália um trilhão de dólares" (MORO, 2004, p.60).

Além disso, de acordo com o Banco Mundial, a prática da corrupção, além de ampliar a exclusão social, 
deteriora os serviços públicos, distorce a aplicação dos recursos que deveriam se dirigir a setores sociais e vitima uma clientela que não pode se socorrer nos serviços privados ou no mercado. Além de minar a estabilidade fiscal e macroeconômica, o que indiretamente atinge a população mais carente, a corrupção gera concentração de renda e força, muitas vezes, exploração e esgotamento de recursos ambientais pela população excluída do progresso econômico pela corrupção. (apud MEDEIROS, 2006, p. 59).

Afora esses efeitos, em países democráticos e subdesenvolvidos, segunda Seña (2001), a corrupção das elites democráticas desses países costumeiramente é citada como argumento para legitimar golpes de Estado. Como exemplo, cita o caso da Junta Militar que em 24 de março de 1976 tomou o poder na Argentina, com a proposta de promover o saneamento moral da República mediante o combate à corrupção, instaurando o período mais trágico da história do país.

A corrupção, desse modo, coloca em risco a democracia, compromete o desenvolvimento dos Estados e enfraquece as instituições nacionais e os valores democráticos. Além do mais, seus elementos, causas e condicionantes proporcionaram vínculos dessa forma de delinquência com outras formas de criminalidade, dentre as quais o crime organizado e a lavagem de dinheiro, penetrando, assim, em diversos setores da sociedade, convertendo-se, inclusive, num fenômeno transnacional.

Diante disso e da ameaça que a corrupção representa para a estabilidade e a segurança das sociedades, sua prática vem sendo criminalizada nos textos jurídicos de diversos países e tem sido objeto de convenções internacionais. Como exemplo, citamse a Convenção Interamericana contra a Corrupção, de 29 de março de 1996, a Convenção sobre o Combate da Corrupção de Funcionários Públicos Estrangeiros em Transações Comerciais Internacionais, concluída em Paris, em 17 de dezembro de 1997, e a Convenção das Nações Unidas contra a Corrupção, adotada pela Assembleia Geral das Nações Unidas em 31 de outubro de 2003, todas ratificadas pelo Brasil.

Conforme disposto no artigo VI, número 1, da Convenção Interamericana contra a Corrupção, promulgado no Brasil por intermédio do Decreto $\mathrm{n}^{\circ} 4.410$, de 7 de outubro de 2002, são atos de corrupção:

a. a solicitação ou a aceitação, direta ou indiretamente, por um funcionário público ou pessoa que exerça funções públicas, de qualquer objeto de valor pecuniário ou de outros benefícios como dádivas, favores, promessas ou vantagens para si mesmo ou para outra pessoa ou entidade em troca da realização ou omissão de qualquer ato no exercício de suas funções públicas; 
b. a oferta ou outorga, direta ou indiretamente, a um funcionário público ou pessoa que exerça funções públicas, de qualquer objeto de valor pecuniário ou de outros benefícios como dádivas, favores, promessas ou vantagens a esse funcionário público ou outra pessoa ou entidade em troca da realização ou omissão de qualquer ato no exercício de suas funções públicas;

c. a realização, por parte de um funcionário público ou pessoa que exerça funções públicas, de qualquer ato ou omissão no exercício de suas funções, a fim de obter ilicitamente benefícios para si mesmo ou para um terceiro;

d. o aproveitamento doloso ou a ocultação de bens provenientes de qualquer dos atos a que se refere este artigo; e

e. a participação, como autor, co-autor, instigador, cúmplice, acobertador ou mediante qualquer outro modo na perpetração, na tentativa de perpetração ou na associação ou confabulação para perpetrar qualquer dos atos a que se refere este artigo. (BRASIL, 2002).

No Código Penal pátrio a prática delitiva foi tipificada de três formas: corrupção passiva, corrupção ativa e corrupção ativa em transação comercial internacional, artigo este incluído pela Lei $\mathrm{n}^{\circ} 10.467$, de 11 de junho de 2002, cuja finalidade era dar efetividade ao Decreto $\mathrm{n}^{\mathbf{0}} 3.678$, de 30 de novembro de 2000, que promulgou a Convenção sobre o Combate da Corrupção de Funcionários Públicos Estrangeiros em Transações Comerciais.

A corrupção passiva, enquanto crime praticado por funcionário público contra administração, foi tipificada no art. 317 do Código Penal nos seguintes termos: "solicitar ou receber, para si ou para outrem, direta ou indiretamente, ainda que fora da função ou antes de assumi-la, mas em razão dela, vantagem indevida, ou aceitar promessa de tal vantagem" (BRASIL, 1940).

Já a corrupção ativa, enquanto crime praticado pelo particular contra a administração pública, tipificada no art. 333 do Código Penal, compreende a prática delitiva de: "oferecer ou prometer vantagem indevida a funcionário público, para determina-lo a praticar, omitir ou retardar ato de ofício" (BRASIL, 1940).

E a corrupção ativa em transação comercial internacional, foi tipificada no art. 337-B do Código Penal nos seguintes termos: "prometer, oferecer ou dar, direta ou indiretamente, vantagem indevida a funcionário público estrangeiro, ou a terceira pessoa, para determina-lo a praticar, omitir ou retardar ato de ofício relacionado à transação comercial internacional” (BRASIL, 1940).

Essa crescente criminalização e constante repressão das práticas corruptas se deve ao fato de que, conforme afirma Valdés (2004), “aceptar la legalidad del soborno sería equivalente a admitir legalmente la destrucción del sistema; algo tan grotesco 
sistémicamente como aceptar la licitud de la revolución o del golpe de Estado" (VALDÉS, 2004, p. 15).

Dessa maneira, do mesmo modo que a corrupção não pode ser completamente extirpada do aparelho estatal, seu combate, pois, deve ser algo "igualmente permanente, que exige constância, perseverança, vontade e estimativas corretas. Da mesma forma que a corrupção necessita de tempo para crescer, há necessidade de tempo para ser debelada" (MEDEIROS, 2006, p. 58).

No entanto, por piores que possam ser seus efeitos e a conduta dos transgressores, que se utilizam do poder que lhes é conferido pelo cargo para exercê-lo em prol da satisfação de interesses pessoais em detrimento do interesse público, não se pode admitir que a repressão à prática delitiva viole os direitos e garantias fundamentais dos investigados, sob pena de inadmissível subversão dos postulados constitucionais que definem os limites inultrapassáveis da atuação estatal em relação aos investigados, gerando, consequentemente, grave comprometimento do Estado Democrático de Direito.

\section{0 combate à corrupção frente aos direitos e garantias fundamentais}

O combate à corrupção, diante de suas características, exige a adoção de determinadas estratégias e a atuação de diversos órgãos em todas as frentes possíveis. Por ser praticada, em determinados casos, por agentes que integram os centros de poder, e, consequentemente, estão investidos no exercício de poder, sendo inclusive, em algumas situações, politicamente importantes, a prova da materialidade, com a apuração da extensão do dano, e a descoberta da autoria dessas condutas ilícitas, não constitui tarefa fácil, demandando a atuação conjunta de diversos órgãos estatais.

As condutas corruptas, além disso, em regra, não são praticadas de maneira grosseira, de fácil detecção. Pelo contrário, conforme afirma Patrick Cacicedo (2017), esses delitos são "cometidos de forma mais elaborada e oculta, além de exigir um adestramento mais sofisticado do autor, que também possui, muitas vezes, algum acesso ao poder político e econômico" (CACICEDO, 2017, p. 4).

A estrutura administrativa do Estado também não contribui para o combate a essa prática delitiva. A submissão de determinados órgãos, como é o caso da Polícia Federal, diante da estrutura hierárquica da administração pública, ao controle de 
autoridade superior, escolhida politicamente, fragiliza a necessária independência para a investigação e a coleta de provas, diante da influência do poder político.

Esses fatores, aliados a dotações orçamentárias insuficientes para os necessários investimentos nos órgãos investigativos e repressivos, somados à complexidade da atividade financeira e à utilização de alta tecnologia pelas organizações criminosas, demonstram a atual "[...] fragilidade das instituições democráticas para fazer face à corrupção, tanto do ponto de vista preventivo como do repressivo" (ALBUQUERQUE, 2006, p. 20).

Neste sentido, conforme adverte Nicolás Becerra (1998):

\begin{abstract}
É indubitável que as novas formas de criminalidade puseram em maior evidência a incapacidade do sistema de investigação dos delitos, fato que confirma a profecia da criminologia crítica, feita há mais de vinte anos. $\mathrm{O}$ sistema é seletivo não só por razões ideológicas, mas por razões inteiramente práticas. Os crimes de colarinho branco são bem mais difíceis de investigar. A complexidade da atividade financeira, as facilidades nas comunicações, o aparecimento de organizações criminosas apoiadas em alta tecnologia, cujo modo de atuação constitui sempre um grande obstáculo à fixação da responsabilidade pessoal etc., já não permitem que a investigação dos fatos ilícitos seja encarada como uma atividade pessoal isolada, muitas vezes burocratizada e carente de meios técnicos. Além do esforço pessoal e das habilidades profissionais, estes desafios exigem um trabalho em equipe a coordenação não só interna do Ministério Público, mas também dos distintos setores estatais e sociais comprometidos com a investigação de atividades ilícitas deste tipo. (BECERRA, 1998, p. 37).
\end{abstract}

Segundo Albuquerque (2006), seria ingênuo pensar que a corrupção, diante da complexidade que envolve sua prática na era da cibereconomia, possa ser apurada e combatida mediante métodos tradicionais de investigação, preestabelecidos para o esclarecimento de delitos que deixam rastros e apontam para uma autoria determinada. Segundo o doutrinador, “onde o espaço é incerto, as regras processuais atinentes à prova perdem densidade normativa e com ela a aptidão para garantir plenamente tanto os interesses da persecução criminal quanto os direitos fundamentais do acusado" (ALBUQUERQUE, 2006, p. 23).

Ainda, continua afirmando o doutrinador que o véu de legitimidade que envolve a corrupção,

como também o poder econômico que a alimenta, criam exigências relativamente à investigação, que a polícia, desaparelhada e dependente, já não mais pode atender. Seja pelo não aparelhamento, seja pela dependência, 
ou por ambas as coisas, o certo é que a investigação exclusivamente policial favorece a impunidade e desacredita a justiça, na exata medida em que a atividade de coleta de provas, face à estrutura hierárquica da instituição policial, está sujeita ao controle de autoridade superior nem sempre interessada no esclarecimento total do delito. (ALBUQUERQUE, 2006, p. 43).

As investigações da Operação Lava Jato, conduzidas pela Polícia Federal, são um bom exemplo disso. Embora instituída como órgão permanente e estruturada em carreira, com, dentre outras, as atribuições constitucionais para exercer com exclusividade as funções de polícia judiciária da União e apurar os crimes contra a ordem política e social, bem como as infrações penais praticadas em detrimento de bens e interesses da União, suas entidades autárquicas e empresas públicas, a Polícia Federal é subordinada ao Ministério da Justiça e Segurança Pública, razão pela qual o Diretor Geral da Polícia Federal presta contas de suas atividades ao Ministro da citada pasta, o qual é escolhido discricionariamente pelo Presidente da República.

Diante disso, inobstante as atribuições constitucionais da Polícia Federal, o combate à corrupção, frente às características dessa prática delitiva, e do seu atual enraizamento nos centros de poder do país, não pode se restringir à atuação exclusiva da Polícia Federal, exigindo a atuação de outros órgãos em todas as frentes possíveis. Desse modo, seu combate incumbe, também,

\begin{abstract}
aos mecanismos constitucionais de controle interno e externo da administração. Tribunais de contas e secretarias de controle têm dever constitucional nesse mister. O Poder Legislativo, não somente por meio de comissões parlamentares de inquérito, mas, sim, no exercício de distintas competências constitucionais - não apenas, mas também, produtoras de normas - é um ator importante e necessário no combate à corrupção. (MEDEIROS, 2006, p. 70).
\end{abstract}

Além dos mecanismos constitucionais de controle, também são responsáveis pelo enfrentamento da corrupção os "sistemas de auditagem das empresas estatais e das autarquias e fundações, as divisões de corregedoria de diversas carreiras de Estado, a Controladoria Geral da União, a Receita Federal, o Banco Central, [...] o Coaf, os serviços de inteligência, entre outros [...]” (MEDEIROS, 2006, p. 70).

Outrossim, considerando que a corrupção corrói a moral social e a ordem jurídica nacional, ameaçando o regime democrático, seu enfrentamento é pauta necessária e obrigatório ao Ministério Público, órgão com autonomia na estrutura do Estado e regido pelos princípios da unidade, indivisibilidade e independência funcional. 
Enquanto instituição essencial à função da justiça, segundo disposto no art. 127, “caput", da Constituição Federal, incumbe-lhe "a defesa da ordem jurídica, do regime democrático e dos interesses sociais e individuais indisponíveis" (BRASIL, 1988).

Além disso, suas características, se comparado com outros órgãos do Estado, auxiliam na luta contra a corrupção. Neste sentido, segundo Medeiros (2006),

a independência, a autonomia e o caráter incondicionado da atuação do Ministério Público são atributos que, indiscutivelmente, somam muito às alianças de combate a corrupção. A capacidade de resistir a ingerências e autonomamente definir sua pauta de atuação, sem componentes externos menos nobres, torna o Ministério Público um forte ator no combate à corrupção. (MEDEIROS, 2006, p. 70).

No entanto, além esses atributos, o atual panorama nacional exige a adoção de um sistema de investigação de delitos federais "próprio dos membros do Ministério Público e que permita otimizar interna e externamente os recursos estatais destinados à investigação deste tipo de delinquência, sem que a busca da eficiência implique a lesão das garantias individuais" (BECERRA, 1998, p. 38).

Desse modo, a estratégia repressora, para ser eficiente e amenizar a influência política que existe em determinados órgãos e sobre determinados agentes, exige a atuação de diversos setores, cada qual com suas dificuldades e atribuições específicas, de modo a tornar possível a investigação e responsabilização dos corrompidos e dos corruptores.

Entretanto, há que se ter cuidado para que a busca constante de eficiência dos órgãos investigativos e a permanente necessidade dos órgãos repressivos de garantir maior efetividade ao direito penal não acarrete a flexibilização ou a supressão de direitos e garantias processuais penais, assegurados constitucionalmente no rol dos direitos e garantias fundamentais.

As características do crime de corrupção levam alguns penalistas a sugerir a adoção de uma atuação diferenciada do direito penal no combate dessa prática. Neste sentido, para exemplificar, Medeiros (2006) afirma que além de investimentos em sistemas de fiscalização, responsabilização e punição, o enfrentamento da corrupção reclama mudanças na legislação, com aumento nas penas, tipificação de más condutas, e a flexibilização dos sigilos telefônico, bancário e fiscal. 
Ainda, Moro (2004), ao tecer considerações sobre a Operação Mãos Limpas, que, segundo o autor, foi uma das mais importantes cruzadas judiciárias contra a corrupção política, ocorrida na Itália nos anos 90, e afirmar já em 2004 que no Brasil encontravam-se presentes várias condições institucionais necessárias para a realização de uma empreitada judicial semelhante à citada Operação, critica o sistema judiciário afirmando que:

\begin{abstract}
o principal problema parece ser ainda uma questão de mentalidade consubstanciada em uma prática judicial pouco rigorosa contra a corrupção, prática que permite tratar com maior rigor processual um pequeno traficante de entorpecente (por exemplo, as denominadas "mulas") do que qualquer acusado por crime de "colarinho branco", mesmo aquele responsável por danos milionários à sociedade. A presunção de inocência, no mais das vezes invocada como óbice a prisões pré-julgamento, não é absoluta, constituindo apenas instrumento pragmático destinado a prevenir a prisão de inocentes. Vencida a carga probatória necessária para a demonstração da culpa, aqui, sim, cabendo rigor na avaliação, não deveria existir maior óbice moral para a decretação da prisão, especialmente em casos de grande magnitude e nos quais não tenha havido a devolução do dinheiro público, máxime em país de recursos escassos. (MORO, 2004, p. 61).
\end{abstract}

Neste sentido, também, para combater a corrupção enraizada nos centros de poder, e sob o argumento da dificuldade em angariar provas e obter a condenação de agentes corruptos, diante das características da prática delitiva e da carga de prova exigida para obter a condenação de agentes politicamente importantes, tenta-se justificar a necessidade de aceitar a implementação de um processo penal de exceção, com a flexibilização das garantias processuais penais e, consequentemente, violação a direitos fundamentais.

A série de investigações e operações desencadeadas e reunidas sob o rótulo de “Operação Lava Jato" vem sendo desenvolvida aos moldes da "Operação Mãos Limpas". De maneira semelhante, há comprometimento ao direito do contraditório e da ampla defesa, quebra do sigilo das investigações e a utilização do chamado "processo midiático", com a divulgação de trechos de elementos da investigação que conduzam à população a formar - por conta própria - um juízo de valor sobre a culpabilidade do investigado, como meio de deslegitimar a classe política e legitimar a atuação mais rigorosa do judiciário.

Deysi Cioccari (2015), ao estudar a questão do escândalo político midiático da “Operação Lava Jato”, no período compreendido entre os anos de 2014 e 2015, e seus reflexos na vida política e social dos envolvidos, identificou que o jornal Folha de $\mathrm{S}$. 
Paulo, objeto do seu estudo, publicou 68 edições relevantes sobre a citada Operação, isso no período de apenas um ano.

Segundo a citada autora, os escândalos midiáticos põem em risco a reputação dos envolvidos e esses "sabem que, além de seu prestígio, há outra grande perda no campo simbólico: o poder e 'sua capacidade de fazer uso da reputação ou bom nome a fim de exigir respeito dos outros e alcançar seus interesses e objetivos"” (CIOCCARI, 2015, p. 68).

Conforme lição de Bruno Martins Ferreira e outros (2014), ao analisarem a influência da mídia nos processos criminais, "as informações transmitidas de forma excessiva e deturpada, nos meios de comunicação, podem agredir outros direitos constitucionais como o direito de defesa, ao contraditório, presunção de inocência, ao devido processo legal, causando assim danos irreparáveis [...]" (FERREIRA et. al. 2014, p. 7).

Além disso, neste sentido, afirma Márcio Thomaz Bastos (1999) que:

Levar um réu a julgamento no auge de uma campanha de mídia é levá-lo a um linchamento, em que os ritos e fórmulas processuais são apenas a aparência da justiça, encobrindo os mecanismos cruéis de uma execução sumária. Trata-se de uma pré-condenação, ou seja, a pessoa está condenada antes de ser julgada [...]. É o processo pelo qual o noticiário da imprensa sobre as investigações em torno de uma pessoa que vai ser submetida a julgamento acaba determinando a culpabilidade ou a inocência da pessoa antes de ela ser julgada formalmente. (BASTOS, 1999, p. 115).

Soma-se a isso o risco de desfigurar a imagem de políticos honestos que, imprudentemente podem ser submetidos à investigação e posterior processo diante de delações premiadas inverídicas ou utilizadas de maneira política para atacar adversários. Há, assim, o risco de lesão indevida à honra dos investigados, diante do furor midiático em divulgar em primeira mão as notícias e garantir o aumento da audiência, antes de qualquer comprovação dos fatos imputados. Mesmo que não seja denunciado ou, mesmo denunciado, seja absolvido, os efeitos danosos para a carreira política são irreversíveis.

Em um momento em que se luta pela implementação da teoria do garantismo penal, com o câmbio do atual modelo processual inquisitório para um modelo processual acusatório, verifica-se a flexibilização de direitos e garantias fundamentais. Com uma legislação processual penal de base autoritária e fascista, com reformas pouco 
significativas no decorrer das décadas, amarga-se o recrudescimento do sistema inquisitório e o distanciamento do almejado garantismo penal.

Neste sentido, Marco Aurélio Nunes da Silveira (2015) afirma que, o "Código de Processo Penal brasileiro é fruto do regime autoritário instalado após a Revolução de 1930, sob a batuta de Getúlio Vargas, denominado de Estado Novo" (2015, p. 264). Ainda, segundo Silveira (2015), embora a comissão nomeada para a elaboração da legislação processual penal fosse composto por importantes juristas, o "resultado foi um código que representava os ideais políticos vigentes ao Estado Novo, declaradamente autoritário e fundado num pretenso pensamento 'popular-democrático'. A base foi o Codice Rocco de processo penal (1930), da Itália fascista de Mussolini [...]" (SILVEIRA, 2015, p. 270).

Aury Lopes Jr., ao tratar do descompasso existente entre o inquérito policial, fruto do regime autoritário de 1937 de caráter fascista, e o garantismo penal da atual Constituição Federal, afirma que:

\footnotetext{
O modelo atual está em crise e não cumpre satisfatoriamente com sua função. Desagrada à defesa, por seu marcado caráter inquisitivo e a prepotência judicial; aos juízes, porque o material proporcionado é imprestável (tanto sob o ponto de vista de valor probatório como também de fonte de informação); e, por fim, também desagrada ao destinatário final - Ministério Público -, pois a demora, as deficiências e o descompasso entre o que realiza a polícia e o que necessita o promotor acabam por prejudicar seriamente a atividade acusatória. Ademais, é ilógico que a polícia investigue sem estar em sincronia com quem vai acusar. É inegável que melhor acusa quem por si mesmo investiga (ou comanda a investigação), da mesma forma que melhor é conduzida a investigação por quem vai acusar. (apud ALBUQUERQUE, 2006, p. 45).
}

Esses fatores, associados às particularidades da corrupção política, podem levar os juízes a assumirem o protagonismo na persecução penal, desequilibrando a relação processual, desenvolvendo uma forma autodefensiva de administração da justiça, com a assunção parcial do papel da acusação, aos moldes do sistema inquisitivo. O magistrado não pode assumir, além da sua função de julgador, as funções de acusador ou defensor, sob pena de ofensa ao Estado Democrático de Direito.

Considerando que o sistema processual penal está inserido e decorre do sistema judiciário, e esse está inserido e decorre do sistema constitucional adotado no país, o primeiro deve assimilar os princípios, direitos e garantias assegurados pelo último. $\mathrm{O}$ Código de Processo Penal, mesmo sendo fruto de um regime autoritário de caráter 
fascista, atualmente está inserido em um ambiente democrático-constitucional, devendo, assim, ter correspondência com o atual Estado Democrático de Direito.

$\mathrm{O}$ respeito aos direitos e garantias fundamentais dos investigados e acusados deve ser buscado incessantemente, para que não se cometam os mesmos erros da Operação Mãos Limpas. Sobre essa Operação, Renzo Orlandi (2016) afirma que depois de dois anos abundantes "de tensão inquisitória, sentia-se a necessidade de um retorno à normalidade, um retorno às garantias processuais, ao respeito pelos direitos de defesa" (ORLANDI, 2016, p. 391).

E continua o citado autor afirmando que, naquele biênio, inúmeros processos foram instruídos,

\begin{abstract}
com defensores que se sentiram privados de direitos percebidos como componentes essenciais de um processo justo, como o direito de interrogar ou contradizer as testemunhas de acusação, o direito de realizar a sua própria investigação alternativa à do Ministério Público, o direito de se defender no processo penal, não em processos midiáticos, tramados por meios de comunicação (imprensa, televisão) impiedosos em apresentar, como culpados, réus talvez destinados a serem absolvidos. (ORLANDI, 2016, p. 392).
\end{abstract}

Além disso, o uso distorcido do processo penal sem o respeito às garantias processuais penais gera tensão entre os Poderes Executivo e Legislativo e o Poder Judiciário, o que pode ocasionar, segundo Orlandi (2016), a criação de um vácuo de poder, o que, segundo o doutrinador, é sempre perigoso em um Estado Democrático de Direito, diante do risco percebido pela opinião pública como uma oportunidade para que o vazio seja preenchido por homens de inspiração autoritária, que naturalmente estariam ao lado do povo.

Desse modo, há que se ter cuidado com a atual onda ainda mais autoritária na persecução penal, utilizada sob o pretexto de ser a única maneira de garantir que a justiça seja feita para os corrompidos e corruptores, para que não se perca o rumo da marcha ao garantismo penal, retrocedendo ao sistema inquisitório puro.

Além do mais, cabe ressaltar que não é apenas com repressão e sanção aos envolvidos que se resolverá este problema grave que assola o país. Os meios preventivos podem se mostrar mais adequados para o enfrentamento deste problema, mesmo após o seu enraizamento nos centros de poder. 
Mais importante que a repressão, é a prevenção. Corrigir as falhas do sistema é mais sábio que utilizar apenas os meios punitivos. Para isso,

\begin{abstract}
forçar a extensão máxima do princípio da publicidade à administração é um imperativo nesse campo. A adoção de práticas de transparência e visibilidade dos processos públicos é mecanismo de prevenção das práticas de corrupção. À luz do dia não se transgridem os valores da administração com a mesma facilidade com que se pode fazê-lo às escuras e à sorrelfa. A imposição de práticas e processos administrativos abertos à pronta verificação, com etapas e ritos que imponham fácil apreciação por qualquer um, é um canal de prevenção de práticas de corrupção. (MEDEIROS, 2006, p. 64).
\end{abstract}

A divulgação detalhada dos orçamentos e dos recursos destinados aos órgãos públicos, bem como dos montantes dispendidos na aquisição de bens, na prestação de serviços e nos gastos com a folha de pagamento, independentemente de qual seja o órgão estatal, é o principal meio de evitar abusos e garantir o exercício do poder de maneira visível, transparente de modo suficiente para preservar a lisura na administração pública e garantir que sua legalidade seja aquilatada pelo povo.

Além disso, segundo Medeiros (2006), outro método de precaução constitui na maior participação cidadã nos processos decisórios, em instâncias de controle social e na fiscalização. Organizações não governamentais e os Conselhos de usuários, segundo a doutrinadora, auxiliam na transparência pública e possibilitam maior proximidade entre os processos públicos e a fiscalização dos cidadãos, afastando pretensões funestas.

Ainda, outro método preventivo são as consultas públicas. Essas, realizadas "antes da tomada de decisões, com a explicitação de todos os interesses em jogo, permitem não só a redução dos riscos de corrupção, como também a proteção das autoridades públicas incumbidas de decidirem em nome da administração pública" (MEDEIROS, 2006, p. 65).

Promover a moralidade administrativa é outro meio adequado e, embora mais demorado para surtir efeito, seus resultados perduram por um prazo mais longo. Neste sentido:

\footnotetext{
A disseminação de informação, e não apenas formação, é um veículo de promoção da moralidade administrativa. A revelação periódica e reiterada à sociedade das cifras e dos custos sociais da corrupção é excelente mecanismo de promoção da moralidade administrativa. A descoberta do volume de recursos desperdiçados e o quanto dos tributos que são apropriados nos esquemas de corrupção não apenas provoca ira e revolta, como se pode esperar, mas conduz à produção de uma consciência social do peso da
} 
corrupção e do quanto é perniciosa sua ocorrência. (MEDEIROS, 2006, p. 67).

Desse modo, a estratégia preventiva processa-se por meio da ampliação da transparência pública que, embora já aplicada, ainda não tornou suficientemente cristalina a gestão e os dispêndios dos recursos públicos, na participação mais ativa da sociedade nos processos decisórios e na fiscalização do emprego das verbas públicas, bem como na realização de consultas públicas antes da tomada de decisões e na promoção da moralidade administrativa.

Por fim, a adoção da estratégia preventiva evita que o combate à corrupção por meio da estratégia repressiva crie riscos para os direitos e garantias fundamentais dos investigados e acusados em geral, bem como atritos nos Poderes do Estado, o que, conforme visto, pode ocasionar um perigoso vácuo de poder e servir de justificativa para a ascensão do autoritarismo e o fim do Estado Democrático de Direito.

\section{Considerações finais}

Verificou-se, na presente pesquisa, que a corrupção está relacionada com os centros de poder, sendo sua prática configurada mediante o exercício de poder de modo abusivo por agentes públicos, pervertendo a coisa pública mediante a prática, abstenção ou retardamento na execução de condutas em desconformidade com o dever funcional e o interesse público, com o intuito do benefício pessoal.

A intensidade da corrupção poderá ser reduzida à medida que sejam afastadas suas causas e oportunidades, pois a amplitude de sua manifestação ocorre conforme a propensão das suas causas e condicionantes serem favoráveis ou desfavoráveis. Conforme estudado, o momento tem sido oportuno para a corrupção, diante da internacionalização dos capitais, da liberalização das relações comerciais, da diminuição do controle estatal sobre o mercado e da formação de organizações empresariais com grande poder econômico.

A expansão da corrupção aperfeiçoou suas características, o que dificulta a obtenção de provas e a responsabilização dos infratores, e pela ameaça que representa para o regime democrático, ao corroer a ordem jurídica e a moral social, o combate à corrupção tem sido utilizado como meio justificador para a flexibilização de garantias 
processuais penais, permitindo o retrocesso nas garantias do Estado Democrático de Direito, em direção ao sistema inquisitório puro.

Para evitar a ascensão da atual onda autoritária na persecução penal, e seus riscos para os direitos e garantias fundamentais e para a própria democracia, diante do perigo iminente de que a existência de um vácuo de poder, gerado pelo atrito entre os Poderes, permita o seu preenchimento por homens de inspiração autoritária, a corrupção deve ser combatida com respeito aos direitos fundamentais, e não apenas por intermédio de estratégias repressivas, mas também com a adoção de estratégias preventivas.

Identificar e corrigir as falhas do sistema, buscar meios mais eficazes de tornar efetiva a transparência pública, promover a informação e a participação da população nos processos decisórios, com maior fiscalização dos órgãos estatais e da classe política, auxilia na diminuição da necessidade de aplicação de estratégias repressivas e evita que sejam colocados em risco direitos e garantias fundamentais e a própria democracia.

A adoção de métodos preventivos, além de tornar o combate à corrupção mais efetivo ao longo do tempo, reduz os gastos e os efeitos negativos da sua repressão, promovendo maior participação popular no controle da administração pública e, por consequência, uma democracia participativa.

\section{Referências}

ALBUQUERQUE, Mário Pimentel. O protagonismo do Ministério Público no Estado de Direito: a cidadania contra a corrupção. In: ALBUQUERQUE, M. P.; MEDEIROS, H. J.; BARBOZA, M. N. (Org.). O papel do Ministério Público no combate à corrupção. Brasília: [s.n.], 2006.

ARISTÓTELES. Política. São Paulo: Martin Claret, 2001.

BARBOZA, Márcia Noll. O combate à corrupção no mundo contemporâneo e o papel do Ministério Público no Brasil. In: ALBUQUERQUE, M. P.; MEDEIROS, H. J.; BARBOZA, M. N. (Org.). O papel do Ministério Público no combate à corrupção. Brasília: [s.n.], 2006.

BASTOS, Márcio Thomaz. Júri e Mídia. In: TUCCI, Rogério Lauria (Coord). Tribunal do Júri: estudo sobre a mais democrática instituição jurídica brasileira. São Paulo: Revista dos Tribunais, 1999. 
BECERRA, Nicolás. EI Ministério Público y los nuevos desafios de la Justicia Democrática. Buenos Aires: Ad Hoc, 1998.

BOBBIO, Norberto; MATTEUCCI, Nicola; PASQUINO, Gianfranco. Dicionário de política. Tradução de Carmen C. Varriale et. al. Vol. I, Brasília: UNB, 1976-1998.

BRASIL. Constituição (1988). Constituição da República Federativa do Brasil. Disponível em: <http://www.planalto.gov.br/ccivil_03/constituicao/constituicaocompila do.htm>. Acesso em: 8 set. 2017.

BRASIL. Código penal (1940): decreto-lei no 2.848, de 7 de dezembro de 1940. Disponível em: <http://www.planalto.gov.br/ccivil_03/decretolei/Del2848compilado.htm>. Acesso em: 17 set. 2017.

BRASIL. Decreto $\mathbf{n}^{\circ}$ 4.410, de 7 de outubro de 2002. Promulga a Convenção Interamericana contra a Corrupção, de 29 de março de 1996, com reserva para o art. XI, parágrafo $1^{\circ}$, inciso "c". Disponível em: $<$ http://www.planalto.gov.br/cci vil_03/decreto/2002/d4410.htm>. Acesso em: 24 set. 2017.

CACICEDO, Patrick. Democracia e processo de criminalização da corrupção no Brasil. Revista Brasileira de Ciências Criminais, São Paulo, vol. 128/2017, p. 409-430, fev. 2017.

CIOCCARI, Deysi. Operação Lava Jato: escândalo, agendamento e enquadramento. Revista Alterjor, São Paulo, v. 2, jun.-dez. 2015. Disponível em: <http://www.revistas.usp.br/alterjor/article/view/aj12-a04>. Acesso em: 01 mar. 2019.

FERREIRA, B. M. et al. A influência da mídia nos processos criminais. Revista Eletrônica de Ciências Jurídicas, Ipatinga, vol. 1, n. 1, 2014. Disponível em: <http://fadipa.educacao.ws/ojs-2.3.3-3/index.php/cjuridicas/article/view/153>. Acesso em: 01 mar. 2019.

MEDEIROS, Humberto Jacques de. O papel do Ministério Público no combate à corrupção. In: ALBUQUERQUE, M. P.; MEDEIROS, H. J.; BARBOZA, M. N. (Org.). O papel do Ministério Público no combate à corrupção. Brasília: [s.n.], 2006.

MORO, Sérgio Fernando. Considerações sobre a Operação Mani Pulite. Revista CEJ (Brasília), v. 26, p. 56-62, 2004. Disponível em: <http://s.conjur.com.br/dl/artigo-moromani-pulite.pdf>. Acesso em: 16 set. 2017.

OLIVEIRA, Gesner. O triângulo perverso da corrupção: corrupção razoável, monopólio e corrupção necessária. In: FERRAZ JÚNIOR, Tércio Sampaio; SALOMÃO FILHO, Calixto; NUSDEO, Fábio (Org.). Poder econômico: direito, pobreza, violência, corrupção. Barueri: Manole, 2009.

ORLANDI, Renzo. Operazione Mani Pulite e seu contexto político, jurídico e constitucional. Revista da Academia Brasileira de Direito Constitucional. Curitiba, 
2016, vol. 8, n. 15, jul.-dez., pp. 378-405. Disponível em:

<http://abdconst.com.br/revista16/operazioneRenzo.pdf>. Acesso em: 16 set. 2017.

SILVEIRA, Marco Aurélio Nunes da. A cultura inquisitória vigente e a origem autoritária do Código de Processo Penal brasileiro. R. EMERJ, Rio de Janeiro, v. 18, n. 67, p. 264-275, jan.-fev. 2015. Disponível em:

<www.emerj.tjrj.jus.br/revistaemerj_online/edicoes/revista67/revista67_264.pdf>.

Acesso em: 24 set. 2017.

VALDÉS, Ernesto Garzón. Acerca de la calificación moral de la corrupción: tan solo una propuesta. Isonomía: Revista de Teoría y Filosofía del Derecho, Cidade do México, n. 21, out. 2004. Disponível em: <http://www.cervantesvirtual.com/descar gaPdf/acerca-de-la-calificacin-moral-de-la-corrupcin-tan-slo-una-propuesta-0/>. Acesso em: 19 set. 2017.

SEÑA, Jorge F. Malem. La corrupción política. Jurídica: anuario del departamento de derecho de la universidad iberoamericana, Cidade do México, n. 31, p. 579-595, 2001. Disponível em: <https://revistas-

colaboracion.juridicas.unam.mx/index.php/juridica/issue/ view/653>. Acesso em: 22 set. 2017. 